\title{
Two Presentation Ways of Complex Numbers Consulting History and Intellectual Interest
}

\author{
수학사와 지적 흥미를 고려한 복소수의 두 가지 제시 방법
}

LEE Gi Don 이기돈 CHOI Younggi 최영기

\begin{abstract}
It has been proposed since modern times that we need to consult the history of mathematics in teaching mathematics, and some modifications of this principle were made recently by Lakatos, Freudenthal, and Brousseau. It may be necessary to have a direction which we consult when modifying the history of mathematics for students. In this article, we analyse the elements of the cognitive interest in Hamilton's discovery of the quaternions and in the history of discovery of imaginary numbers, and we investigate the effects of these elements on attention of the students of nowadays. These works may give a direction to the historic-genetic principle in teaching mathematics.
\end{abstract}

Keywords: elements of cognitive interest, breach of canonicity, historic-genetic principle; 지적 흥미의 요소, 통념의 위반, 역사 발생적 원리.

MSC: 00A35, 97C20, 97D80 ZDM: C20

\section{1 서론}

수학 교수학습에서 유클리드 원론의 연역적인 전개 방법에 대한 대안으로 수학사를 참 고하여야 한다는 주장은 16세기 Ramus 이래로 꾸준히 제기되었다. 역사 발생적 원리 를 주장한 근대의 이론은 수학사와 개인의 연속적이고 평행적인 인지 발달을 가정하고 수학사에서 드러나는 개념 발생 과정을 개인의 수학 학습에 적용하고자 하였다. 그러나 수학사가 연속적이지 않을 뿐만 아니라 수학사와 개인의 인지발달 사이에 완전한 평행 성을 가정하기 어렵다는 지적이 제기되어 왔다[18, p. 410-412; 3; 7].

현대에 역사 발생적 원리를 새롭게 해석한 Lakatos, Freudenthal, Brousseau 등은 수학사를 불연속적인 도약의 역사로 보고 학생의 상황에 맞게 재구성하여 도입할 것을 주장하였다. 이들은 수학사를 보는 관점에 따라 서로 다른 교수학적 대안을 내 놓았는

LEE Gi Don: Dept. of Math. Edu., Seoul National Univ. E-mail: tracer0@empal.com CHOI Younggi: Dept. of Math. Edu., Seoul National Univ. E-mail: yochoi@snu.ac.kr Receiveded on May 3, 2013, revised on July 3, 2013, accepted on July 13, 2013. 
데, Lakatos는 수학사를 증명과 반박의 역사로 보았고, Freudenthal은 현상으로부터의 수학화에 주목했으며 Brousseau는 인식론적 장애를 극복할 수 있는 교수학적 상황을 중시하여 역사 발생적 원리의 변용을 꾀하였다[18, p. 412-415].

이러한 이론에도 불구하고 역사 발생적 원리를 교수학습에 실제로 적용할 때 지도 단원을 구체적으로 구성하는 것은 쉽지 않은 일이다[19, p. 568-569]. 그것은 수학 개 념의 역사적 발생의 파악이 쉽지 않기 때문이기도 하지만 그것을 파악했다고 하더라도 학생의 상황에 맞는 적절한 변용이 어렵기 때문이기도 하다. 단순한 수학사의 반복에서 그치지 않기 위해서는 적절한 변용에 대한 보다 구체적인 기준이 설정될 필요가 있다고 생각된다.

수학사를 수학 교육에 활용하자는 주장은 그것이 자연스러운 학습의 흐름이라는 생각 과 함께 학생의 흥미를 유발할 수 있을 것이라는 기대를 포함한다. 그러나 근대의 역사 발생적 원리를 주장한 이론 뿐만 아니라 그것을 변용한 현대의 이론들도 역사 발생적 원리의 적용이 학생의 흥미를 어떻게 유발하며 그것이 자연스러운 수학 학습과 어떠한 관계가 있는지에 대해서는 주목하지 않았다. 학습 내용에 대한 지적 흥미는 수학 학습의 강력한 내적 동기가 된다는 점에서 수학자들이 그 문제에 대해 갖고 있었던 지적 흥미를 분석하고 그것이 오늘날의 학생에게 작동할 수 있도록 수학사를 변용하여 적용하는 것이 필요하다.

본 논문에서는 Hamilton의 사원수의 발견 사례와 허수 발견의 역사를 통해 수학자와 수학사에 흐르는 사고에서 지적 흥미의 요소를 분석하고, 교수학습에서 그것을 고려하 여 복소수를 제시하는 두 가지 방법과 그 장단점을 논의하고 수업 내용이 비교적 손실 없이 전달되는 영재학급 학생들을 대상으로 교수실험을 함으로써, 역사 발생적 원리를 적용하는 교수학습의 실제에 시사점을 얻고자 한다.

\section{2 수학자의 사고에서 지적 흥미 -Hamilton 의 사례-}

\section{1 지적 흥미 요소}

Kintsch[8]는 독자가 텍스트에서 느끼는 흥미를 정서적 흥미 (emotional interest)와 인 지적 흥미 (cognitive interest)로 구분하였다. 정서적 흥미는 폭력이나 성과 같이 자극적 인 정서적 영향 때문에 관심을 환기하는 흥미 또는 영웅에 대한 이야기처럼 그것 자체가 문맥 속에서 또는 텍스트 바깥에서 정서적이기 때문에 얻어지는 흥미를 의미한다. 이에 비해 인지적 흥미는 이야기에서 묘사되는 사건들의 복잡한 패턴, 그때 발생하는 놀라움, 그것이 말해지는 방법 때문에 야기되는 매력적인 흥미를 뜻한다. Kintsch는 인지적 흥 미가 텍스트의 내용에 대한 독자의 사전 지식, 각 문단이 독자에게 일으키는 불확실성, 
문단의 전체 텍스트에 대한 사후정합성 (postdictability) 등의 요소에 의해 결정된다고 주장하였다.

한편 Bruner[5]는 패러다임적 사고와 내러티브적 사고를 구분하고 그 동안 교육이 지나치게 패러다임적 사고에 치중함으로써 세계에 의미를 부여하는 사고를 소홀히 하 였음을 지적하면서 내러티브적 사고의 교육적 중요성을 주장하였다. 내러티브적 사고 는, 귀납적으로 추측하여 가설을 세우고 실험을 하거나 논리 수학적으로 그것을 정당 화하는 패러다임적 사고와는 달리, 반드시 참은 아니더라도 그럴듯한 이야기를 만들고 이해하는 사고이다. 그런데 Bruner [3, p. 12]에 따르면 Labov and Waletzsky [11]가 내러티브의 언어학적인 구조를 무엇이 발생했는지 (what happens)와 그것을 말할 만한 이유(why it is worth telling), 즉 청자가 그것을 들을 만한 이유로 구성된다고 본 것 은 중요한 통찰을 제공한다. 특히 후자에 대해 Bruner [2, 3]는 독자가 어떤 이야기를 들을 가치가 있다고 판단하는 이유는 그것이 ‘통념의 위반(breach of canonicity)' 을 포함하기 때문이라고 지적한다.

더욱이, 거의 언제나 이야기는 우리가 직면하는 예외들이 어떤 가능한 세계 속에서 말이 되거나 “의미” 를 가지는 그러한 가능한 세계에 대한 이야 기일 것이다. 만일 누군가가 우체국에 들어와서 성조기를 펼쳐 흔들기 시작 한다면, 당황스러워 하는 당신의 의문에 대해 일상심리학적인 대화 상대자는 당신에게, 오늘이 자신이 잊고 있었던 국경일이거나 지역 재향군인지부가 모금행사를 하는 것이거나 또는 단순히 깃발을 든 사람이 오늘 아침 타블 로이드 신문의 어떤 기사 때문에 상상력이 자극된 애국주의자일 것이라고 말할 것이다[2, p. 49].

위 인용과 같이 통념에서 벗어나는 사태에 접한 사람은 여러 가지 가능한 이야기를 만들어 통념의 위반을 해소하고자 한다. 그리고 통념의 위반을 포함한 이야기는 청자의 흥미를 유발하여 사안의 의외성이 어떻게 해결되는지에 대해 관심을 갖게 한다. 이야 기를 말하는 것은 사건을 나열하여 그 불균형을 해명하고 이야기된 사건들을 평가하는 것이다[4].

통념의 위반이 이야기에 말하고 들을 만한 가치를 주는 요소라는 Bruner의 지적은 사건들의 복잡한 패턴과 놀라움 등 말하는 방법에 따라 텍스트에 대한 인지적 흥미가 발생한다는 Kintsch의 생각에 구체성을 부여한다. 즉, 통념의 위반이 부각되는 방식으 로 말해진 이야기가 인지적 흥미를 유발한다는 설명이 가능하다. 그런데 통념의 위반은 비단 일상적인 이야기에만 흥미를 부여하는 것은 아니다.

Peirce는 대표적인 논리적 추론 방법인 연역법과 귀납법 외에 문제 해결의 과정에서 자연스럽게 사용하는 가추법(abduction) 도 일종의 추론 방법임을 지적하였다. 예기치 
못한 놀라운 사실을 과학적으로 설명하기 위해서는 어떤 예측으로부터 필연적이거나 개연적으로 그 사실에 이르러야 하는데, 가추법은 이러한 예측의 단계로서 가설을 채 택하는 추론과정이다[9, p. 153]. 이것은 기존의 규칙들에 형식논리를 적용하여 결론을 추론하는 연역법과 여러 가지 사례를 관찰하여 일반적인 원리를 도출하는 귀납법과는 다른 것으로서, 예기치 못한 사태에 직면하여 기존의 규칙을 바탕으로 그 사태를 설명 해주는 적절한 가설을 세우는 사고이다[7, p. 374; Table 1]. 가추법은 추론 방법 중에 하나이지만 가추적 사고는 예기치 못한 사태, 즉 통념의 위반에 의해 발생한다는 점에서 Bruner의 설명과 상통하는 면이 있다. 요컨대, 통념의 위반은 지적 흥미를 유발하는데 그것이 논리 과학적인 사고를 자극하면 가추에 의한 가설이 생성되고 내러티브적인 사 고를 자극하면 그럴듯한 이야기가 생성된다고 할 수 있다.

통념의 위반이 말해진 다음에는 그 위반에 대한 적절한 해소가 인지적 흥미를 유지시 킬 수 있다[10, p. 410]. 통념의 위반을 한 번의 설명으로 완전히 해소하지 않고 여전히 미해결된 의문을 남김으로써 서스펜스가 형성된다. Kintsch가 인지적 흥미를 결정하는 요소로 지적한 각 문단이 독자에게 일으키는 불확실성도 서스펜스에 의한 흥미의 유발 을 의미하는 것으로 볼 수 있다. 적절한 틈을 두고 진행되는 이야기와 설명은 통념의 위반에 의해 발생한 인지적 흥미를 지속시키는 역할을 하며, 따라서 최종적인 해소로서 결말의 내용도 주요 관심의 대상이 된다.

\begin{tabular}{|c|c|c|c|c|c|c|}
\hline $\begin{array}{l}\text { 사고 } \\
\text { 순서 }\end{array}$ & \multicolumn{2}{|r|}{ 연역법 } & \multicolumn{2}{|r|}{ 귀납법 } & \multicolumn{2}{|r|}{ 가추법 } \\
\hline 1 & 규칙 & $\begin{array}{c}\text { 이 가방 안의 모든 } \\
\text { 콩들은 흰색이다 }\end{array}$ & 사례 & $\begin{array}{c}\text { 이 콩들은 이 } \\
\text { 가방에서 꺼냈다 }\end{array}$ & 규칙 & $\begin{array}{c}\text { 이 가방 안의 모든 } \\
\text { 콩들은 흰색이다 }\end{array}$ \\
\hline 2 & 사례 & $\begin{array}{c}\text { 이 콩들은 이 } \\
\text { 가방에서 꺼냈다 }\end{array}$ & 결과 & 이 콩들은 흰색이다 & $\begin{array}{c}\text { (예기치 } \\
\text { 못한) } \\
\text { 결과 }\end{array}$ & 이 콩들은 흰색이다 \\
\hline 3 & 결과 & 이 콩들은 흰색이다 & 규칙 & $\begin{array}{c}\text { 이 가방 안의 모든 } \\
\text { 콩들은 흰색이다 }\end{array}$ & $\begin{array}{l}\text { 사례 } \\
\text { (가설) }\end{array}$ & $\begin{array}{c}\text { 이 콩들은 이 } \\
\text { 가방에서 꺼냈다 }\end{array}$ \\
\hline
\end{tabular}

Table 1. Peirce's abduction; Peirce의 가추법

\subsection{Hamilton 의 사고에서 지적 흥미}

이상의 논의를 바탕으로 지적 흥미 요소의 측면에서 역사 발생적 원리를 적용하기 위해 서 수학사에 흐르는 발견의 사고 과정을 분석할 필요가 있을 것이다. 일반적으로 수학적 발견의 과정은 여러 수학자들이 오랜 시간에 걸쳐 이루어낸 것이기 때문에 그 집합적인 사고 과정을 구체적으로 파악하기 어려운데 비해 수학자 개인의 사고 과정은 보다 용 이하게 파악할 수 있다고 생각된다. 특히 Hamilton은 편지와 일기 등으로 자신의 탐구 
과정을 상세히 기록하고 있어서 수학자가 어떤 사실에 지적 흥미를 느꼈는지를 파악하 기에 알맞다. 또 그의 사원수 이론의 착상은 3장에서 분석할 복소수의 역사 발생과도 밀접한 관계를 가지고 있다. 이러한 이유에서 Hamilton의 사원수 발견 과정을 지적 흥 미 요소의 측면에서 분석한다.

Hamilton은 복소수 곱셈의 기하적 모델과 유사하게 삼차원 공간의 triple $(a, b, c)$ 들 사이의 곱셈을 정의하는 문제에 관심을 가지고 연구하던 중 사원수를 발견하였다. 사 원수를 발견하기까지의 Hamilton의 사고 과정은 일기, 동료 수학자 Graves에게 쓴 편 지, Royal Irish Academy의 프로시딩에 소개된 논문, 사원수에 대한 강의 노트, 죽음 을 앞두고 아들에게 쓴 편지 등을 통해 알 수 있다[17]. Van der Waerden [17]은 이 기록을 바탕으로 Hamilton 의 사원수 발견의 과정을 다섯 가지 시도로 정리하고 있다 (Table 2). Hamilton은 두 triple ${ }^{1)}$ 의 곱 $(a+b i+c j)(x+y i+z j)$ 에 분배법칙, 교환법칙, $i^{2}=j^{2}=-1^{2}$ 등을 적용하여 $(a x-b y-c z)+(a y+b x) i+(a z+c x) j+(b z+c y) i j$ 를 얻었는데 이로부터 미지의 대상 $i j$ 의 의미를 밝히는 문제가 대두되었다.

$i j$ 의 의미를 밝히려는 첫 번째 시도로서 Hamilton은 $i^{2} j^{2}=1$ 이라는 데 착안하여 $i j$ 를 1 또는 -1 로 추측하였다. 그러나 이 추측은 두 triple의 절댓값 ${ }^{3)}$ 의 곱이 곱의 절댓값과 같지 않아 거부되었다. 두 번째 시도에서는 triple의 더 간단한 곱인 제곱 $(a+b i+c j)^{2}=$ $a^{2}-b^{2}-c^{2}+2 a b i+2 a c j+2 b c i j$ 와 등식 $\left(a^{2}+b^{2}+c^{2}\right)^{2}=\left(a^{2}-b^{2}-c^{2}\right)^{2}+(2 a b)^{2}+(2 a c)^{2}$ 으로부터 $i j$ 를 0 으로 추측하였다. 이 추측은 절댓값의 법칙 (the law of moduli) ${ }^{4}$ 을 만족 시킬 뿐 아니라 편각의 법칙 (the law of argument) ${ }^{5}$ )까지 만족시켰다. ${ }^{6)}$

그러나 $i j=0$ 이라는 추측에서 이상하고 불편한 느낌7)을 받은 Hamilton은 세 번째 시도에서 $i j=0$ 이라는 추측을 버리고 대신 참신한 상상력을 발휘한다. $i$ 와 $j$ 의 곱에 대한 교환법칙을 포기하고 $i j=-j i$ 라고 가정하면 $(a+b i+c j)^{2}$ 의 전개식이 절댓값의 법칙과 편각의 법칙을 만족시키는 것을 발견한 것이다. 그러나 $i j$ 의 의미는 여전히 알 수 없었기 때문에 Hamilton은 $i j=-j i=k$ 라고 놓고 탐구를 계속하였다. 네 번째 시도는 $i j=-j i=k$ 라 가정하고

$$
(a+b i+c j)(x+b i+c j)=\left(a x-b^{2}-c^{2}\right)+i(a+x) b+j(a+x) c+k(b c-b c)
$$

1) 해밀턴은 평면 위의 점 $(a, b)$ 를 복소수 $a+b i$ 꼴로 표현하듯이 공간 위의 점 $(a, b, c)$ 를 $a+b i+c j$ 꼴로 표현하였다.

2) Hamilton은 $i^{2}=-1$ 인 것과 마찬가지로 $j^{2}=-1$ 라고 생각했다.

3) $\sqrt{a^{2}+b^{2}+c^{2}}$ 과 $\sqrt{x^{2}+y^{2}+z^{2}}$

4) 두 수의 절댓값의 곱은 두 수를 곱한 수의 절댓값과 같다는 것을 의미한다.

5) 두 복소수의 편각의 합은 두 복소수를 곱한 복소수의 편각과 같다는 것을 의미한다.

6) $\frac{c}{b}=\frac{2 a c}{2 a b}$ 이므로 $a+b i+c j$ 와 $a^{2}-b^{2}-c^{2}+2 a b i+2 a c j$ 는 실수축을 포함하는 한 평면 위에 있다.

7) $|i||j|=1 \cdot 1=1 \neq 0=|0|=|i j|$ 에서 보듯이 $i j=0$ 이라는 추측은 절댓값의 법칙을 만족시키지 않는다. 
에서 절댓값의 법칙과 편각의 법칙이 성립함을 관찰한 것이다. 이로써 Hamilton은 $i j=$ $-j i$ 라는 확신을 갖게 되었다.

다섯 번째 시도는 일반적인 두 triple의 곱

$$
(a+b i+c j)(x+y i+z j)=(a x-b y-c z)+i(a y+b x)+j(a z+c x)+k(b z-c y)
$$

와 등식

$$
\left(a^{2}+b^{2}+c^{2}\right)\left(x^{2}+y^{2}+z^{2}\right)=(a x-b y-c z)^{2}+(a y+b x)^{2}+(a z+c x)^{2}+(b z-c y)^{2}
$$

의 관찰로부터 얻어졌다. 그는 다음과 같이 기록하였다.

그리고 이때 우리가 triple을 계산하기 위해서는 어떤 의미에서 4차원 공간 을 받아들여야 한다는 것이 이해되기 시작하였다 $[15$, p. $108 ; 20$, p. 230 에서 재인용].

즉, Hamilton은 3차원 공간의 triple $a+b i+c j$ 가 아니라 quadruple $a+b i+c j+d k$ 를 연산의 대상으로 해야 한다는 것을 깨달았다. 이때 $i k=i i j=-j, k j=i j j=-i$ 로 설정 하고 $i j=-j i$ 와 유사하게 $k i=j, j k=i$ 로 놓았으며, 이로부터 $k^{2}=i j i j=-i i j j=-1$ 을 얻었다. 그리고 두 quadruple의 곱 $(a+b i+c j+d k)\left(a^{\prime}+b^{\prime} i+c^{\prime} j+d^{\prime} k\right)$ 를 전개하여 그 결과가 quadruple이 되고 절댓값의 법칙을 만족시키는 것을 확인함으로써 사원수의

\begin{tabular}{|c|c|c|c|}
\hline $\begin{array}{l}\text { 사고 } \\
\text { 순서 }\end{array}$ & 사고 내용 & 통념의 위반 A & 통념의 위반 B와 해소 \\
\hline 1 & $\begin{array}{l}i^{2} j^{2}=1 \text { 로부터 } i j \text { 를 } 1 \text { 또는 } \\
-1 \text { 로 추측 }\end{array}$ & & \\
\hline 2 & $\begin{array}{l}\text { 절댓값의 법칙으로부터 } i j \text { 를 } 0 \\
\text { 으로 추측 }\end{array}$ & & \\
\hline 3 & $\begin{array}{l}(a+b i+c j)^{2} \text { 의 전개식과 } \\
\text { 절댓값의 법칙으로부터 } i j= \\
-j i(=k) \text { 으로 추측 }\end{array}$ & $\begin{array}{l}\text { 통념(교환법칙)에서 } \\
\text { 벗어나는 사고의 시작 }\end{array}$ & \multirow{2}{*}{$\begin{array}{l}\text { 통념의 위반(의미가 분명하지 } \\
\text { 않은 } k \text { 가 절댓값의 법칙과 } \\
\text { 정합적임) }\end{array}$} \\
\hline 4 & $\begin{array}{l}(a+b i+c j)(x+b i+c j) \text { 의 } \\
\text { 전개식과 절댓값의 법칙으로 } \\
\text { 부터 } i j=-j i(=k) \text { 를 확신 }\end{array}$ & 통념(교환법칙)의 위반 & \\
\hline 5 & $\begin{array}{l}(a+b i+c j)(x+y i+z j) \text { 의 전 } \\
\text { 개식과 절댓값의 법칙으로부터 } \\
k(=i j=-j i) \text { 를 quadruple } \\
(0,0,0,1) \text { 로 추측 }\end{array}$ & & $\begin{array}{l}k \text { 에 의미를 부여함8)으로써 통 } \\
\text { 념의 위반이 해소됨 }\end{array}$ \\
\hline
\end{tabular}
발견을 완성하였다.

Table 2. The process of Hamilton's thought and relieving breach of canonicity; Hamilton의 사고 과정 및 통념의 위반과 해소 
이와 같은 다섯 가지 시도에서 두 가지 통념의 위반을 발견할 수 있다.

〈통념의 위반 A : 의미가 분명한 대상의 성질이 기존의 수학적 통념과 다름〉

Hamilton 에게 $i$ 와 $j$ 는 각각 3 차원 공간의 두 triple $(0,1,0)$ 와 $(0,0,1)$ 을 의미하는 것 이었지만 $i j$ 의 성질을 알지 못하다가 세 번째 시도와 네 번째 시도를 통해서 $i j=-j i$ 를 추측하고 확신하게 됐다. 그런데 $i j=-j i$ 는 연산은 교환법칙이 성립해야 한다는 기존의 수학적 통념을 결정적으로 위반하는 성질이다. Hamilton은 교환법칙이라는 수학적 통념 에서 벗어나는 $i$ 와 $j$ 의 곱의 성질을 발견함으로써 분배법칙과 절댓값의 법칙에 정합적인 곱 연산을 정의하였다.

〈통념의 위반 B : 의미가 분명하지 않은 대상이 기존의 수학적 법칙과 정합적임〉

Hamilton은 네 번째 시도에서도 $k$ 의 의미를 파악하지 못했다. 그러나 $k=i j=-j i$ 라는 $k$ 에 관한 성질의 적용은 $(a+b i+c j)^{2}$ 과 $(a+b i+c j)(x+b i+c j)$ 의 전개식에서 모두 절댓값의 법칙을 만족시켰다. 즉, 의미도 분명하지 않은 대상 $k$ 의 성질을 적용한 결 과가 기존에 인정되어 온 절댓값의 법칙에 정합적이었던 것이다. 이것은 정체가 불분명한 대상은 합법칙적으로 행동하기 어렵다는 상식적인 통념에 대한 위반으로 볼 수 있다. 다섯 번째 시도에서 $k$ 의 정체가 quadruple $(0,0,0,1)$ 로 밝혀지면서 이 통념의 위반은 해소된다.

Bruner의 견해에 따르면 Hamilton과 수학자들은 이 두 가지 통념의 위반에 지적 흥미를 느꼈을 개연성이 크다. 실제로 Boyer and Merzbach[1, p. 947-948] 는 교환법칙이 성립 하지 않는 수체계의 발견(〈통념의 위반 $\mathrm{A} 〉)$ 을 수학에 엄청난 자유를 부여한 것으로 평가하 였고, Hamilton은 $k$ 의 의미를 알지 못하는 상황에서도 $k$ 의 성질 $k=i j=-j i$ 가 기존의 수학과 정합적이라는 점에서 그 성질을 확신할 정도로〈통념의 위반 B〉에 주목하였다.

\section{3 허수의 역사 발생에서 지적 흥미}

Cardano는 더해서 10 이 되고 곱해서 40 이 되는 두 수를 $5 \pm \sqrt{-15}$ 으로 표현함으로써 수학사에서 처음으로 음수의 제곱근을 상상했지만, 그것을 쓸모도 없고 괴변적인 수라고 하면서 즉시 거부했다. 판별식이 0보다 작은 이차방정식이 실근을 갖지 않는다는 것은 명백한 사실이었고, 존재하지 않는 것의 형식적 표현은 수학자들의 관심을 끌지 못했다[13, p. 55].

8) $k$ 에 quadruple의 의미를 부여하는 것 자체가 두 수 $i, j$ 의 곱이 3차원 공간에 닫혀있다는 통념에 대한 위반이다. 이 통념의 위반이 수단이 되어 통념의 위반 B가 해소된다. 
허수가 수학자들의 관심을 끈 것은 그것이 존재하지 않는 수임에도 불구하고 기존의 수학 적 사실들과 정합적이면서도 유용한 결과들을 산출해 냈기 때문이다. Cardano의 삼차방정 식의 근의 공식을 $x^{3}=15 x+4$ 에 적용한 것에 대한 Bombelli의 해석이 그 대표적인 사례이 다. Cardano의 근의 공식에 의하면 위 방정식의 근은 $x=\sqrt[3]{2+\sqrt{-121}}+\sqrt[3]{2-\sqrt{-121}}$ 인데, Bombelli는 실수의 연산법칙을 그대로 적용하여 $(2 \pm \sqrt{-1})^{3}=2 \pm 11 \sqrt{-1}$ 을 얻고 따라서 Cardano의 공식이 $x=(2+\sqrt{-1})+(2-\sqrt{-1})=4$ 로서 시행착오를 통해 얻은 방정식의 해 ${ }^{9}$ 와 일치한다고 주장하였다. 한편, 오일러는 정수방정식 $x^{2}+2=y^{3}$ 의 좌 변을 $(x+\sqrt{-2})(x-\sqrt{-2})$ 로 인수분해하고 소인수분해의 유일성10)에 의해 $x \pm \sqrt{-2}=$ $(a \pm b \sqrt{-2})^{3}$ 이라고 추측함으로써 자연수 해가 $x=5, y=3$ 뿐임을 증명하는데 허수를 사용하였다[13, p. 55-57].

Girard와 Descartes는 허수를 사용하여 모든 방정식을 일차식으로 분해할 수 있다고 가정함으로써 대수학의 기본정리와 유사한 생각을 품게 되었는데, 이것은 대수이론 전체에 통합성, 일관성, 간결성을 부여해 주었다. Girard는 이러한 생각을 $x^{4}=4 x-3$ 을 만족하 는 $x$ 에 대하여 $(x+1)^{2}+2$ 의 모든 양수의 값을 구하는 문제 등에 적용함으로써 허수를 유용하게 사용할 수 있었다. 또, 데카르트는 이러한 생각을 바탕으로 근과 계수의 관계 등을 포함하는 방정식 이론을 전개해 나갔다[13, p. 59-61].

이와 같이 수학자들은 허수가 수학적인 정합성과 유용성을 주는 경험을 쌓아가면서 존재 하지 않는 수의 형식적 사용을 용인하게 되었다. 수학자들은 의미가 분명하지 않은 허수가 정합적이고 유용한 결과를 주는 것에 대해〈통념의 위반 B〉를 느꼈을 개연성이 크다. 이 통념의 위반은 허수의 의미가 밝혀짐으로써 해소될 수 있는 것으로서, 실제로 수학자들은 Wessel, Argand, Warren, Gauss 등에 의해 복소수의 기하적 모델이 발견 ${ }^{11)}$ 된 후에야 비로소 허수를 완전히 받아들일 수 있었다[12].

이상에서 간단히 살펴본 허수의 역사를 통해서 허수는 인간 상상력의 창조적 힘과 유용 성을 단적으로 보여주는 사례임을 알 수 있다. 허수(虛數, imaginary number)는 헛되고 공허 (空虛) 한 수라기 보다는 아직 알지 못하는 세계에 존재할지 모르는 상상(imagination) 의 수이면서도 동시에 유용한 수였다. 미지의 수였지만 그것의 사용이 정합적이고 유용하 다는 점에서 수학자들은 그 수의 사용에 대한 유혹을 뿌리치기 어려웠음은 물론 그 수의 의미를 상상하면서 흥분과 고뇌를 동시에 느꼈을 것이다. 이러한 점에서 ‘虛數’ 라는 용어 는 'imaginary number' 라는 용어가 가지고 있는 허수의 긍정적 모습을 충분히 드러내지 못하는 측면이 있다고 생각된다.

9) $1,2,3, \cdots$ 등을 $x$ 에 차례로 대입하여 $x=4$ 가 $x^{3}=15 x+4$ 의 근임을 알 수 있다.

$10)$ 오일러는 $a+b \sqrt{-2}$ ( $a, b$ 는 정수)가 유일인수분해정역(UFD) 임을 증명하지는 않았다.

11) Hamilton도 1833년 아일랜드 학술원에 제출한 논문에서 복소수를 실수의 순서쌍으로 나타내고 곱을 회전 으로 해석하였다[13, p. 947]. 
한편, 허수의 역사에서 수학자들이 느꼈을〈통념의 위반 B〉는 허수의 기하적 모델의 발견과 함께 비로소 해소된 것으로서 통념의 위반 못지않게 기하적 모델도 지적 흥미의 중요 요소였음을 알 수 있다. 그러나 7차 및 2007 개정 수학과 교육과정은 복소수의 기하적 모델을 삭제함으로써 통념의 위반이 주는 주의 환기의 효과를 감소시킬 수 있다고 생각된 다. 2009 개정 수학과 교육과정에서는 심화과목인 고급수학 II의 ‘복소수와 극좌표' 에서 이러한 내용이 다루어지지만 심화과목을 선택하지 않는 대다수의 학생들은 여전히 그러한 문제에 노출될 것으로 보인다.

\section{4 복소수의 두 가지 제시 방법과 지적 흥미}

이상의 논의를 바탕으로 수학 교수학습에서 복소수를 제시하는 두 가지 방법을 제안하고 그 장단점을 지적 흥미와 관련하여 논의한 후 실제로 영재학급을 대상으로 교수 실험하여 확인하였다.

〈제시 방법 1 : 발생적 접근 (genetic approach)〉

(1) 허수에 실수의 연산법칙을 적용할 때의 수학적 정합성과 유용성 제시

(2) 기하적 해석 제시

〈제시 방법 1 〉은 허수 개념의 역사적 발생 순서와 동형으로 복소수를 제시하는 방법이다. 이것은 허수의 기하적 해석을 모르는 상태에서 연산법칙만을 적용하여 복소수를 형식적으 로 다룰 때에 얻어지는 정합성과 유용성을 경험시킴으로써 Hamilton 의 사례에서 보았던 〈통념의 위반 B〉를 통해 지적 흥미를 유발한 후, 복소수의 기하적 해석을 제시하여 그것을 해소하는 내용 전개 방법이다. 보다 구체적인 교수단원의 내용 전개는 Table 3 과 같다.

\begin{tabular}{|c|c|c|}
\hline $\begin{array}{l}\text { 제시 } \\
\text { 순서 }\end{array}$ & 교수학습 내용 & 통념의 위반과 해소 \\
\hline 1 & 시행착오 방법으로 $x^{3}=15 x+4$ 의 근 구하기 & \multirow{6}{*}{$\begin{array}{l}\text { 통념의 위반 B : 의미가 } \\
\text { 분명하지 않은 대상이 } \\
\text { 정합적이고 유용한 결과를 } \\
\text { 산출함 }\end{array}$} \\
\hline 2 & Cardano의 삼차방정식의 근의 공식 제시 & \\
\hline 3 & $x^{3}=15 x+4$ 에 삼차방정식의 근의 공식 적용 & \\
\hline 4 & 근의 공식의 적용 결과에 대한 Bombelli의 해석 & \\
\hline 5 & 정수방정식 $x^{2}+2=y^{3}$ 에 대한 오일러의 풀이 소개 & \\
\hline 6 & 의미가 분명하지 않은 허수의 유용성에 대한 토의 & \\
\hline 7 & 복소수의 기하적 해석 제시 & 통념의 위반의 해소 \\
\hline
\end{tabular}

Table 3. The first way of presenting complex number; 복소수의 제시 방법 1 
허수 개념 발생의 역사에서 수학자들은 제곱해서 음수가 되는 수의 존재성이 아니라 의미가 분명하지 않은 대상이 정합적이고 유용한 결과를 주는 것에 통념의 위반을 느꼈다. 그러나 허수의 형식적 사용의 정합성 및 유용성 뿐만 아니라 복소수의 기하적 모델을 파악 하고 있는 현대 수학의 입장에서는 제곱해서 음수가 되는 수가 확실히 존재하고, 이것은 실수의 성질에 익숙한 학생에게는 통념의 위반 ${ }^{2}$ )이다. 〈제시 방법 2〉는 알려진 수학적 사실들을 종합적으로 고려하여 이러한 통념의 위반을 부각시키기 위한 것이다.

〈제시 방법 2 : 종합적 접근(synthetic approach)〉

(1) 평면에서 곱셈의 의미에 대한 문제 제기

(2) $i^{2}=-1<0$ 의 논증 제시

\begin{tabular}{|c|c|c|}
\hline $\begin{array}{l}\text { 제시 } \\
\text { 순서 }\end{array}$ & 교수학습 내용 & 통념의 위반 \\
\hline 1 & 수직선에서 덧셈과 곱셈(특히 제곱)의 의미 제시 & 제곱한 수는 양수라는 통념을 확인 \\
\hline 2 & 평면에서 덧셈의 의미 제시 & \\
\hline 3 & 평면에서 곱셈의 의미에 대한 문제 제기 & \\
\hline 4 & $(a, b)(c, d)=(a c, b d)$ 라는 정의의 문제점 ${ }^{13)}$ 탐구 & \\
\hline 5 & $\begin{array}{c}(a+b i)(c+d i)=a c+(a d+b c) i+b d i^{2} \text { 에서 } i^{2} \text { 의 } \\
\text { 의미에 대한 문제 제기 }\end{array}$ & \\
\hline 6 & 절댓값의 법칙을 이용한 $i^{2}=-1$ 의 논증 ${ }^{14)}$ & \multirow{2}{*}{$\begin{array}{l}\text { 통념의 위반 A : 의미가 분명한 } \\
\text { 대상의 성질이 기존의 수학적 } \\
\text { 통념과 다름 }\end{array}$} \\
\hline 7 & 제곱해서 음수가 되는 수의 존재에 대한 토의 & \\
\hline
\end{tabular}

Table 4. The second way of presenting complex number; 복소수의 제시 방법 2

〈제시 방법 2〉는 평면의 점이라는 구체적 대상에 대하여 특히 $(0,1)$ 의 제곱이 논리 수 학적으로 음수이어야 함을 보임으로써 Hamilton의 사례에서 보았던〈통념의 위반 A〉를 통해 지적 흥미를 유발한다. 이것은 Hamilton이 3차원 공간의 두 점 $i$ 와 $j$ 에 대해 $i j$ 를 결정하는 과정에서 $i j=-j i$ 를 발견한 것과 유사한데, Table 4 는 이를 참고하여 구체화한 교수단원의 내용 전개 방법이다.

〈제시 방법 1〉은 허수의 역사 발생 과정을 동형으로 제시함으로써〈통념의 위반 B〉를

12) 수의 제곱은 양수라는 수학적 통념에 대한 위반이다.

13) $(1,0),(0,1)$ 과 같은 영인자가 존재하여 나눗셈이 잘 정의되지 않는다.

14) $(a+b i)(c+d i)=a c+(a d+b c) i+b d i^{2}$ 에서 $i^{2}=e+f i$ 로 놓는다.

이 식이 모든 실수 $a, b, c, d$ 에 대해서 성립하도록 실수인 상수 $e, f$ 를 결정한다.

$a=0$ 으로 놓으면, $b^{2}\left(c^{2}+d^{2}\right)=b^{2} d^{2} e^{2}+(b c+b d f)^{2}$ 에서 $f=0$

따라서 $i^{2}=e$ 로 놓으면, $\left(a^{2}+b^{2}\right)\left(c^{2}+d^{2}\right)=(a c+b d e)^{2}+(a d+b c)^{2}$ 에서 $e=-1$

그러므로 $i^{2}=-1<0$ 이다. 
부각시키고자 하였다. 이것은 고전적인 역사 발생적 원리에 보다 충실함으로써 수학자들의 사고 과정을 따라가면서 그들의 고뇌와 기쁨 등을 경험할 수 있다는 장점이 있을 것이다. 그러나〈제시 방법 1〉에서 지적 흥미를 유발하는 주요 수단인〈통념의 위반 B〉는 수학사적 으로는 의미가 불분명한 허수 사용의 정합적이고 유용한 결과가 긴 시간을 두고 쌓이면서 형성된 것으로서 이러한 통념의 위반을 비교적 짧은 시간 안에 교수학습 상황에서 구현하는 데에는 어려움이 있을 것으로 생각된다. 한편, 〈순서7〉에서 복소수의 기하적 해석을 제 시함으로써〈통념의 위반 B〉 가 해소되면 서스펜스가 일단락되고 지적 흥미가 마무리되기 때문에 추가적인 탐구 문제나 질문의 발생을 위축시키는 단점이 있을 것으로 보인다.

〈제시 방법 2〉는 종합적인 접근으로〈통념의 위반 A〉를 부각시키고자 하였다. 〈통념의 위반 $\mathrm{A}$ 〉는 〈통념의 위반 B〉와는 달리 구체적인 대상의 성질이 기존의 수학적 통념에 위반 되는 것으로서 보다 직접적인 놀라움을 환기시킬 수 있을 것으로 기대된다. 또, 〈순서6〉 와 〈순서 7 〉에서 $(0,1)$ 의 제곱이 음수가 되어야 함을 논증하고 토의함으로써 교수 단원을 마치지만, 그것이 통념의 위반이기 때문에 곱셈의 의미와 같은 새로운 관심을 자극하여 추가적인 탐구를 유발할 수 있을 것이다. 그러나 허수 개념의 역사적 발생에서 드러났던 수학자들의 창의적인 아이디어를 풍부하게 다루지 못하는 단점이 있을 것으로 보인다.

실제로 2013년 4월 서울의 한 고등학교 1학년 영재학급 학생 20명을 대상으로 위 두 가지 수업을 차례로 교수실험을 하였다. 이 영재학급은 단위 학교의 학생들을 대상으로 선발하여 일주일에 하루 꼴로 방과 후에 소집되어 교육받는 학급으로서 전국 단위로 모집하는 영재 학교나 시도 단위로 학생을 모집하는 과학고등학교에 비해 영재성은 부족했지만 수학을 비롯한 주요 교과에 대해 높은 학습의욕을 가지고 있었다. 일반 학급은 다양한 학생들을 배려하는 과정에서 수업 내용을 손실 없이 효과적으로 전달하는데 어려움이 있으므로 높은 학습의욕을 갖는 영재학급을 대상으로 교수실험 하였다.

같은 날 1 교시에는 〈제시 방법 1〉을, 2 교시에는 〈제시 방법 2〉를 수업하였다. 학생들은 학교 수업에서 아직 복소수를 공부하지 않았지만 사교육 등의 선행학습을 통해서 복소수에 대한 학습 경험이 있었다. 수업이 끝난 직후 수업 교사(본 연구자)는 수업 후기를 작성하였 고 학생들에게는 Table 5의 문항으로 구성된 질문지를 나누어 주고 1 주일 후에 총 19 부를 수거하였다. 학생들의 흥미가 수업 내용을 기반으로 한 것인지를 확인하기 위한 1-1과 2-1 문항의 응답은 두 학생을 제외하고 양호하였다. ${ }^{15)}$

질문지 분석 결과 1 교시 수업에 대해서는 〈통념의 위반 B〉에 대한 흥미 (8명), 허수 발견 과정의 인간적 측면에 대한 흥미 (6명), 삼차방정식의 근의 공식의 존재에 대한 흥미 (2명) 등을 확인하였고 무응답 또는 타당하지 않은 응답(3명)도 있었다.

15) 한 학생은 1-1에 “복소수의 발명” 이라고 짧게 답하고 2-1에는 응답하지 않았다. 다른 학생은 2-1에 응답하지 않았다. 


\begin{tabular}{|c|l|l|}
\hline 번호 & \multicolumn{1}{|c|}{ 문항 } & \multicolumn{1}{c|}{ 조사 내용 } \\
\hline $1-1$ & 1교시 수업의 줄거리는 무엇인가요? & 1교시 수업의 내용 \\
\hline $1-2$ & $\begin{array}{l}\text { 1교시 수업에서 흥미롭거나 놀라웠던 내용 } \\
\text { 을 그 이유와 함께 적어 주세요 }\end{array}$ & 1교시 수업에서 흥미로운 점 \\
\hline $2-1$ & 2교시 수업의 줄거리는 무엇인가요? & 2교시 수업의 내용 \\
\hline $2-2$ & $\begin{array}{l}\text { 2교시 수업에서 흥미롭거나 놀라웠던 내용 } \\
\text { 을 그 이유와 함께 적어 주세요 }\end{array}$ & 2교시 수업에서 흥미로운 점 \\
\hline 3 & $\begin{array}{l}\text { 두 가지 수업 중 더 마음에 드는 수업과 그 } \\
\text { 이유를 적어 주세요 }\end{array}$ & 둘 중 더 흥미로운 수업과 그 이유 \\
\hline
\end{tabular}

Table 5. The contents of questionnaire; 질문지의 조사 내용

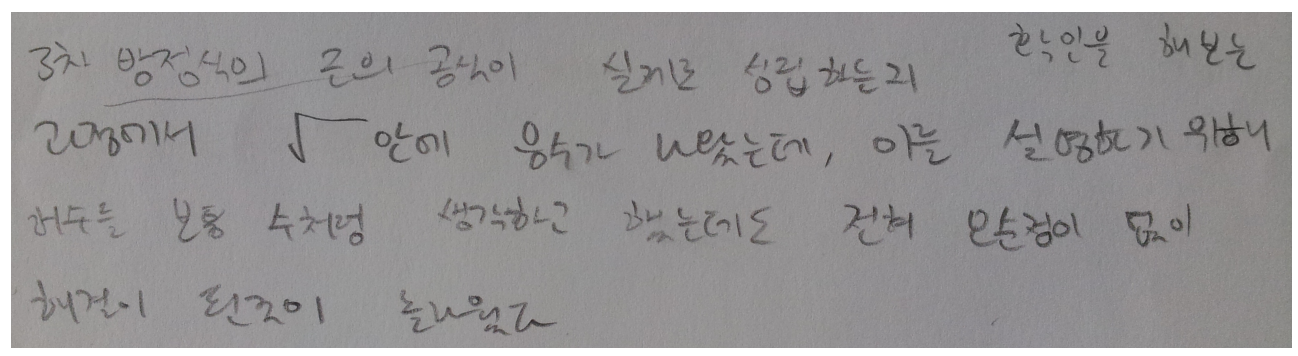

예상과는 달리 짧은 수업에서 수학사의 두 가지 사례만을 살펴보았음에도 위 학생의 응답 과 같이〈통념의 위반 B〉에 대해 흥미를 느끼는 학생을 확인할 수 있었다. 이것은 수업에서 다룬 삼차방정식의 근의 공식에 대한 Bombelli의 해석이 그러한 통념의 위반을 보여주는 전형적인 사례라는 점, 그리고 수업 교사가 그 사례의 의미를 다음과 같이 강조하여 설명한 점과 무관하지 않다고 생각된다.

이때 Bombelli도 $\sqrt{-1}$ 이 무엇인지에 대해서는 알지 못했음을 강조하여 언급했다. $\cdots$ 이러한 특별한 현상이라는 것이 무엇인지에 대해서 학생들에게 물었다. $\cdots$ 한 학생이 의미가 없는 대상이 기존의 결과와 잘 맞는 결과를 산 출하는 것이라고 하였다. 내가 그 학생의 대답을 보충하여 $\cdots$ 더 구체적으로 언급하였다. 그리고 그와 유사한 예가 200년에서 250년 가량 이어졌다는 것을 말해 주었다[교사의 수업 후기].

또한 다음과 같은 학생의 응답은 학생 자신이 직접 수학 지식을 구성하지는 않았지만 수학사를 통해 인간 노력의 산물로서의 수학의 인간적 측면에 관심을 가질 수 있다는 것을 시사한다. 이러한 관심은 수학 내용 자체에 대한 것과는 거리가 있지만 수학 교과 일반에 대한 긍정적 정서를 함양하는데 효과적이라고 생각된다.

2 교시 수업에 대해서는 복소수와 그 연산의 기하적 표현에 대한 흥미 (6명), $i^{2}=-1$ 의 


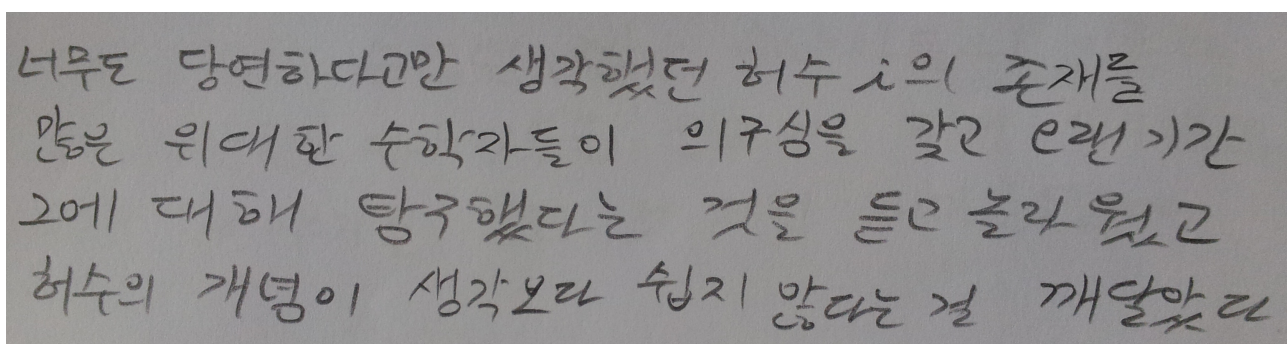

증명에 대한 흥미 (6명), 이 두 가지 모두에 대한 흥미 (3명) 등을 확인할 수 있었다. ${ }^{16)}$ 또, $(a, b)(c, d)=(a c, b d)$ 라는 정의의 문제점에 대한 흥미 (1명)와 무응답 또는 타당하지 않은 응답(3명)도 있었다.

예상과는 달리 제곱해서 0 보다 작은 대상이 존재한다는 의미에서〈통념의 위반 $\mathrm{A}$ 〉에 흥미를 보이는 응답은 찾기 어려웠다. 이것은 학생들이 이미 복소수의 학습 경험을 가지고 있어서 제곱해서 음수가 되는 수에 익숙하기 때문으로 해석된다. 그러나 다음 두 학생들의 응답을 통해 복소수와 그 연산을 구체적인 의미 없이 형식적인 규칙으로만 다루었던 학생에 게 평면이라는 복소수 모델의 존재와 $i^{2}=-1$ 의 증명은 적지 않은 놀라움이었음을 확인할 수 있다.

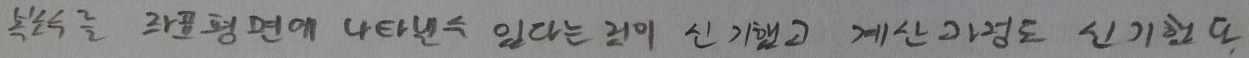

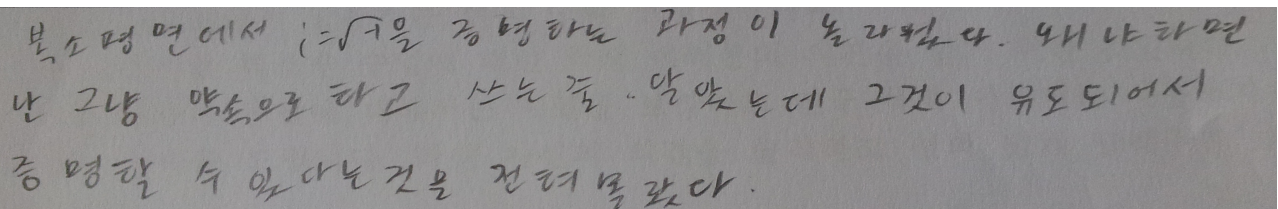

복소수의 기하적 표현은 1 교시의 후반부에 제시된 것으로 2 교시의 주요 내용은 아니었 지만, 2 교시에 다룬 평면의 점에 대한 연산이 복소수의 연산으로 이해될 수 있다는 점을 고려하면 학생들이 1 교시의 후반부에 느낀 깊은 흥미를 2 교시 문항에 표현한 것으로 생각 된다. 이런 관점에서 보면 복소수의 기하적 표현에 대한 흥미는 1 교시에 부각됐던 〈통념의 위반 B>의 해소 또는 선행학습에서 이루어졌을 반복적인 복소수의 형식적 계산에서 오는 건조함의 해소와 관련되는 것으로 보인다.

한편, 학생들은 제곱해서 음수가 되는 구체적인 대상을 알지 못하다가 그러한 대상이 평면 위의 점 $(0,1)(=i)$ 로 존재하고 그 제곱이 논리 수학적으로 -1 이 되어야 한다는 것에 놀라움을 느꼈다. 이러한 흥미는 제곱해서 -1 이 되는 특별한 성질이 단지 약속이 아니라

16) 1 교시 수업에서 복소수의 기하적 해석을 다루었으므로, 2 교시에서 다룬 평면의 점에 대한 연산은 자연스럽게 복소수의 연산으로 받아들여졌을 것으로 생각된다. 
실제 대상의 필연적인 성질이라는 것에 대한 놀라움으로서〈통념의 위반 $\mathrm{A}$ 〉에 가깝다고 생각된다.

마지막으로 두 수업 중 더 흥미로운 수업을 묻는 문항에 대해서는 2 교시가 11 명, 1 교시가 5 명, 무응답 또는 타당하지 않은 응답이 3명이었다.

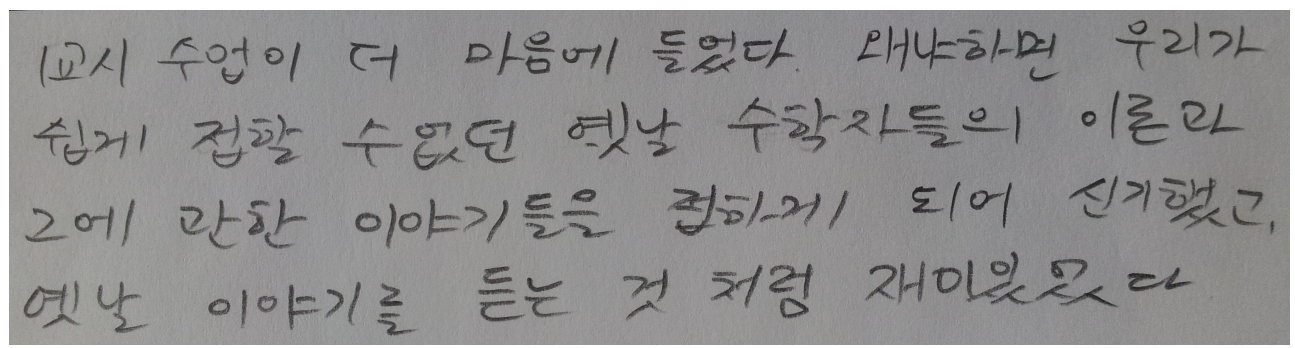

위 응답과 같이 어떤 학생들은 수학사의 이야기적 측면을 흥미로워 하였다. 수학사 관련 이야기에 대한 흥미는 수학 내용 자체에 대한 것과는 거리가 있지만 수학 교과 일반에 대한 긍정적 정서를 향상시킨다는 점에서 의미가 있다고 생각된다.

한편 다소 어려운 내용일지라도 그것이 통념의 위반을 부각시킨다면 학생들의 지적 흥 미를 자극할 수 있음을 다음 학생의 응답에서 확인할 수 있다. ${ }^{17)}$

\section{12+1

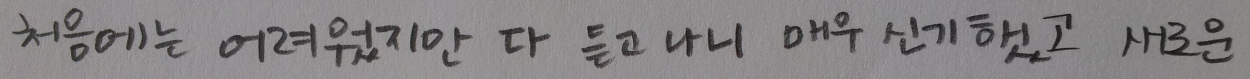

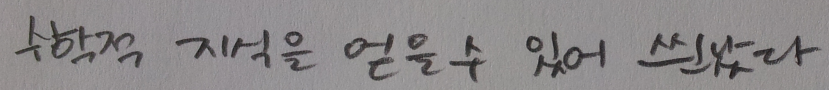

이러한 반응은 쉬운 것과 흥미로운 것 또는 어려운 것과 재미없는 것이 논리적인 관계를 갖는 것은 아니라는 것을 보여준다는 점에서 교육부가 최근 표방한 '쉽고 재미있게 배우는 수학' [14, pp. 16-20]에 대해 시사하는 바가 있다고 생각된다.

이상에서 허수의 역사 발생에 기초한〈통념의 위반 $\mathrm{B}$, 발견의 인간적 측면, 이야기적 요소 등이 학생에게 매력적일 수 있고, 한편으로 복소수의 기하적 해석과 종합적인 접근에 기초한〈통념의 위반 $\mathrm{B}$ 〉의 해소와 〈통념의 위반 $\mathrm{A}$ 〉가 형식적 정의와 기계적 계산에 지친 학생들에게 적지 않은 지적 흥미를 유발할 수 있음을 살펴보았다. 그럼에도 그 동안의 교 육과정에서〈통념의 위반 B〉와 그 해소가 부각된 적이 없을 뿐만 아니라 2009 개정 수학과 교육과정에서도 복소수의 기하적 해석에 대한 접근 기회가 고급수학 II를 선택하는 일부 학생들에게만 주어지는 것은 안타까운 일이라고 생각된다.

17 ) 그러나 어떤 학생은 2 교시의 계산이 너무 길어서 1 교시가 더 마음에 들었다고 응답하기도 하였다. 


\section{5 결론}

Branford는 역사발생적 원리를 수학 교육에 도입할 것을 주장하면서도 인류와 개인의 기하 적 지식의 발달 사이에 필연적인 평행성을 증명하려고 하기보다 이 원리가 교사의 창조적인 작업 속에 내재되어야 함을 강조하였다[20, p. 416-417]. 이것은 역사발생적 원리를 실제로 적용할 때 교사는 수학사의 시간적인 순서에만 집착하기 보다는 그것의 유익함을 수업에 녹여내야 한다는 것으로 해석될 수 있을 것이다. 본 연구에서는 특히 수학자와 수학사에 흐르는 사고에서 드러나는 지적 흥미 요소에 주목하여, 그러한 측면에서 두 가지 복소수 제시 방법을 제안하고 장단점을 논의하는 한편, 수업 내용이 비교적 손실 없이 전달되는 영재학급 학생들을 대상으로 교수실험하고 그 응답을 분석함으로써 역사발생적 원리의 실제 적용에 시사점을 얻고자 하였다.

Bruner와 Peirce의 견해를 종합하면 통념의 위반은 어떤 이야기에 들을 만한 가치를 주는 지적 흥미 요소로서 내러티브적 사고 또는 논리 과학적 사고를 유발하여 그럴듯한 이야기 또는 합리적인 가설을 생산한다. Hamilton의 사원수 발견의 사고 과정에서 구체 적인 의미를 갖는 대상의 성질이 기존의 수학적 통념에서 벗어나는〈통념의 위반 $\mathrm{A}$ 〉와 의미가 불분명한 대상이 기존의 수학적 사실들과 정합적인 〈통념의 위반 B〉를 발견할 수 있었다. 허수 개념의 역사 발생은 수학자들이 200 년 넘는 기간 동안 〈통념의 위반 B〉를 경험하면서 쌓아온 허수의 의미에 대한 지적 흥미가 19 세기 초 복소수의 기하적 해석을 통해 해소되는 역사였다. 이러한 역사발생적인 지적 흥미 요소를 고려한 복소수의〈제시 방법 1 〉과 현대수학의 종합적인 관점에서〈통념의 위반 $\mathrm{A}$ 〉를 부각시킨 복소수의〈제시 방법 2〉를 교수실험하고 영재학급 학생의 반응을 분석하였다. 결과적으로〈제시 방법 1〉 과〈제시 방법 2〉는 각각 〈통념의 위반 B〉와 그 해소에 대한 흥미, 그리고〈통념의 위반 A〉 에 대한 흥미를 유발하는데 일정 부분 효과가 있었으며, 영재학급 학생들은 수학사를 통해 수학의 인간적 측면과 이야기적 측면에 관심을 가질 수 있고, 어려운 내용이더라도 통념의 위반이 부각되면 지적 흥미를 느낄 수 있다는 것을 확인하였다. ${ }^{18)}$ 이 때 수학의 인간적 측 면과 이야기적 측면은 수학 내용 자체에 대한 흥미라기보다는 수학사 관련 이야기에 대한 흥미로서, 수학사를 기반으로 하는 수업은 수학 내용에 대한 지적 흥미 외에도 수학 교과 일반에 대한 긍정적 정서를 함양시킬 수 있는 것으로 보인다.

이상의 결과는 영재학급 학생을 대상으로 한 교수실험에 의한 것이므로 일반 학생들에 게도 적용 가능하다고 결론짓는 것은 지나친 일반화일 것이다. 그러나 본 연구의 영재학급 학생들은 단위 학교를 대상으로 모집된 학생들로서 탁월한 영재성보다는 높은 학습 의욕을

18) 그러나 통념의 위반과 같은 흥미 요소의 형식적 제시보다 더 소중한 것은 그것을 부각시키는 교사의 열정 이라고 생각된다. 실제로 한 학생은 두 가지 수업 중 더 흥미로운 수업을 묻는 문항에 “선생님의 열정이 더 좋았다"고 응답하였다. 
갖춘 학생들이다. 또, 교수실험에서 다루었던 수학 내용은 현재 또는 이전 교육과정에서 일반 학생들을 대상으로 편성되었던 내용이다. 이러한 점에서 복소수의 두 가지 제시 방법이 일반 학생들에게도 지적 흥미를 유발할 것으로 기대되지만 추가적인 확인은 필요하다고 생각된다.

역사발생적 원리를 적용하려는 주장들은 개인에게 자연스러운 사고 순서와 방법을 수학 사로부터 얻고자 하지만, 수학자들의 사고와 탐구는 그들의 지적 흥미로부터 유발되었음에 주목할 필요가 있을 것이다. 본 연구는 수학자와 수학사에서 드러나는 지적 흥미 요소인 두 가지 통념의 위반을 교수단원의 핵심 요소로 변환하여 제시함으로써 그것이 오늘날의 학생들에게도 흥미 요소로 작동할 수 있는 가능성을 살펴보았다는 점에서 의의를 갖는다.

본 연구는 통념의 위반이라는 지적 흥미 요소와 복소수라는 내용 영역을 집중적으로 다루었다. 다양한 지적 흥미 요소와 내용 영역에서 수학사나 수학을 분석하여 수학 자체의 매력을 드러내고 교수학습의 실제에 시사점을 제시하는 더 많은 연구가 이루어지기를 기대 한다.

\section{참고 문헌}

1. C. B. Boyer and U. C. Merzbach, A history of mathematics, John Siley \& Sons, Inc., 1968. C. B. Boyer and U. C. Merzbach, 양영오, 조윤동 역, 「수학의 역사(하)」, 경문사, 2000. (원저는 1968년 출판).

2. J. Bruner, Acts of Meaning, Harvard University Press, 1990.

3. J. Bruner, "The Narrative Construction of Reality", Critical Inquiry 18(1) (1991), 1-21.

4. J. Bruner, The Culture of Education, Harvard University Press, 1996. J. Bruner, 강현석, 이자현 역, 「교육의 문화, 교육과학사, 2005. (원저는 1996년 출판).

5. J. Bruner, Actual Minds, Possible Worlds, Harvard University Press, 1986. J. Bruner, 강 현석, 이자현, 유제순, 김무정, 최윤경, 최영수 역, 「교육 이론의 새로운 지평: 마음과 세계를 융합하기」, 교육과학사, 2011. (원저는 1986년 출판).

6. H. Halberstam and R. E. Ingram Hamilton (Eds.), The Mathematical Papers of Sir William Rowan Hamilton, vol. III, Algebra, Cambridge University Press, 1967.

7. C. Hartshorne and P. Weiss (Eds.), Collected Papers of Charles Sanders Peirce, Vol. 2, Elements of Logic, Thoemmes Press, 1932/1998.

8. W. Kintsch, "Learning from Text, Levels of Comprehension, or Why Anyone Would Read a Story Anyway", Poetics 9(1980), 87-98.

9. Kang M. J., "A Study on C. S. Peirce's Semiotics: For a New Philosophy of Art History", Unpublished doctoral thesis of SNU, 2007. 강미정, "C. S. 퍼스의 기호학 연구: 신미술사의 철학을 위하여”, 서울대 박사학위 논문, 2007.

10. S. Klassen, "The Construction and Analysis of a Science Story: A Proposed Methodology", Science and Education 18(2009), 401-423.

11. W. Labov and J. Waletzsky, "Narrative Analysis: Oral Version of Personal Experience", Essays on the Verbal and Visual Arts (J. Helm Ed.), Seattle: University of Washington Press, 
1967, 12-44.

12. Lee D. H., "Evolution of Geometric Interpretation of Complex Number : Focused on Descartes, Wallis, Wessel”, The Korean Journal for History of Mathematics 20(3) (2007), 5972. 이동환, “복소수의 기하적 해석의 발달: Descartes, Wallis, Wessel를 중심으로", 한국수 학사학회지 20(3) (2007), 59-72.

13. Lee D. H., "Development of the concept of complex number and it's educational implications", The Korean Journal for History of Mathematics 25(3) (2012), 53-75. 이동환, "복소수 개념의 발달과 교육적 함의”, 한국수학사학회지 25(3) (2012), 53-75.

14. Ministry of Education, Science and Technology, The Ways of Reinforcing Public Education and Reducing Private Education, released on May 19, 2011. 교육과학기술부, 「공교육 강화-사교육 경감 선순환 방안」, 2011.5.19. 배포자료.

15. Min S. Y. and Joung Y. J., "On the historic-generic principle: focused on representations", The Proceeding of Conference of the Study of Mathematics Education (2003), 1-10. 민세 영, 정연준, “역사발생적 원리에 대한 고찰: 재현 개념을 중심으로”, 수학교육학연구 발표대회 논문집 (2003), 1-10.

16. Yoo Y. J., "On Critically Amending of the Learning Principles of History of Mathematics”, The Korean Journal for History of Mathematics 15(1) (2002), 109-114. 유윤재, "역사발생 적 원리의 비판적 수용에 대하여”, 한국수학사학회지 15(1) (2002), 109-114.

17. B. L. Van der Waerden, "Hamilton's Discovery of Quaternions", Mathematics Magazine 49(5) (1976), 227-234.

18. Woo J. H. and Min S. Y., "A study on historico-genetic principle of teaching and learning in mathematics”, The Journal of Educational Research in Mathematics 12(3) (2002), 409-424. 우정호, 민세영, "역사발생적 수학 학습-지도 원리에 관한 연구”, 수학교육학연구 12(3) (2002), 409-424.

19. Woo J. H., Min S. Y., and Joung Y. J., "A Study on the Historic-Genetic Principle of Mathematics Education(2)-History of Mathematics in the Teaching of Mathematics and Mathematics Teachers Education”, School Mathematics 5(4) (2003), 555-572. 우정호, 민세 영, 정연준, "역사발생적 수학교육 원리에 대한 연구(2)—수학사의 교육적 이용과 수학교사 교육”, 학교수학 5(4) (2003), 555-572.

20. Woo J. H., Park M. A., and Kwon S. I., "A Study on the Historic-Genetic Principle of Mathematics Education(1) - A Historic-Genetic Approach to Teaching the Meaning of Proof”, School Mathematics 5(4) (2003), 401-420. 우정호, 박미애, 권석일, “역사발생적 수 학교육 원리에 대한 연구(1) - 증명의 의미 지도의 역사발생적 전개”, 학교수학 5(4) (2003), 401-420. 